\title{
Knowledge and associated factors of lactational amenorrhea as a contraception method among postpartum women in Aksum town, Tigray Region, Ethiopia
}

Teklehaymanot Huluf Abraha1*, Alemayehu Shimeka Teferra², Abebaw Addis Gelagay²,

Tsehaynesh Gidey Welesamuel ${ }^{1}$, Gezienesh Kahsay Fisseha' ${ }^{1}$, Berihu Gidey Aregawi ${ }^{1}$ and Desta Siyoum Belay ${ }^{3}$

\begin{abstract}
Objectives: The objective of the study was to assess the prevalence of knowledge level and predictors of lactational amenorrhea method (LAM) as method of contraception among women who gave birth a year prior to the study period in the Aksum town, Tigray Region. The study was cross sectional in design conducted from March 25 to April 24,2015 . Results of the study could help the design of family planning strategies.

Results: The knowledge status of LAM as a contraceptive method was 8.8\% [95\% $\mathrm{Cl} 6.4-11 \%)]$. Women who delivered at health institution ( $A O R=1.4,95 \% \mathrm{Cl} 1.2-4.3$ ), attended postnatal care ( $A O R=1.3,95 \% \mathrm{Cl} 1.2-3.0)$ and visited home and counseled about family planning by health extension in the last 12 months, ( $A O R=1.5,95 \% \mathrm{Cl} 1.3-4.0)$ were more likely found knowledgeable towards LAM. Secondary and above level of the maternal education was also found a significant predictor variable with $L A M$ as a contraceptive method ( $A O R=1.295 \% \mathrm{Cl} 1.1-4.0$ ). Our findings recommend that to address the knowledge gap of mothers; improving the uptake of maternal health services and strengthening family planning counseling at home are a key area for improving the knowledge level of LAM.
\end{abstract}

Keywords: Lactational amenorrhea method, Knowledge, Contraception, Aksum, Tigray, Ethiopia

\section{Introduction}

The lactational amenorrhea method (LAM) is a highly effective for preventing subsequent pregnancy (98\%) during the first 6 months postpartum method of contraception for postpartum women [1-5]. The development of LAM began in 1988 when a group of experts from around the world met in Bellagio, Italy to define a set of guidelines that a woman could use to predict her return to fertility during breast feeding [6]. LAM should have three criteria to be used; exclusively breast feeding a child who is less than 6 month old and mother should be amenorrhea $[2,3]$.

\footnotetext{
*Correspondence: teklehaymanothuluf@gmail.com

1 School of Public Health, College of Health Sciences, Aksum University, P.O.Box: 1010, Aksum, Tigray, Ethiopia

Full list of author information is available at the end of the article
}

Worldwide, more than 90 percent of women during the post partum period desire either to delay or limit their next pregnancies [7]. Most of postpartum women want to prevent pregnancy during first 2 years after delivery, but had not yet received any contraceptive method [8].

In Ethiopia, maternal health problems remain a major public health problem since pregnancy and child birth are the leading cause of mortality and morbidity among the sexually active women $[9,10]$. Half of all non first pregnancies occur less than 1 year following preceding birth [11]. At national level, there is high level of unmet need for family planning in the first year following delivery (i.e. 80\%) [12]. LAM is a natural defense against pregnancy, in expensive contraceptive, safe for mothers [2], and provide ideal nutrition and defense against infection and disease for infants [5]. It increases a subsequent adoption of other modern contraceptive methods. Since 
counseling on LAM includes information on transition to other modern contraceptive methods once LAM criteria are no longer met, LAM has the potential to increase uptake of contraception after is no longer effective $[5,6$, 13, 14].

Despite the benefit provided by exclusive breast feeding to women as an important condition to LAM and for the survival of infants, and increasing knowledge regarding LAM as a method of contraception and we can simply avert unwanted pregnancy by adopting LAM $[5,6]$. However; LAM in Ethiopian Health Sector Transformation Plan (EHSTP) agenda has less emphasized [10]. To our knowledge; the LAM knowledge status in Ethiopia particularly in urban community has not been studied, where fertility rate is generally high [9] and health resources extremely limited [10]. We therefore; sought to assess the knowledge level and predictors of LAM as method of a contraception among women gave birth in the past 1 year prior to the study period. This could help family planning planners to develop strategies for the prevention of closely spaced, unintended pregnancies and maximizing use of LAM as a method of contraceptive method in the first 6 months.

\section{Main text \\ Methods}

\section{Study design and period}

This was a community based cross sectional study survey done in the Aksum town, Tigray Region, northern Ethiopia, from March 25 to April 24, 2015.

\section{Study setting}

Aksum town is the study area. It is located $1067 \mathrm{~km}$ to the north of Addis Ababa, the capital city of Federal Democratic Republic of Ethiopia, and $248 \mathrm{~km}$ from Mekelle city of Tigary Regional State. According the town administrative health office the estimated total population 60,706, of whom 30,960 are women living in five Kebeles. Majority of the population depends on none agriculture production. The town has achieved universal health coverage. There are two public health centers, one referral hospital, one zonal hospital, one Family Guidance Association of Ethiopia clinic, five private clinics and ten drug shops providing maternal, child and other health services to the population [15].

\section{Sources population}

All reproductive age women who gave birth in the last 12 months prior to the study period (March 25, 2014March 25, 2015) who living in the town of Aksum were taken as sources population.

\section{Study population}

All reproductive age women who gave birth in the last 12 months who living in the town of Aksum during the data collection period.

\section{Sample size determination and procedures}

A single sample proportion formula was used to determine the sample size considering the following assumptions: Since there is no a study done in the study area or Ethiopia, the proportion women who have a knowledge on LAM in extended postpartum period was assumed to be $50 \%, 95 \%$ confidence intervals, $5 \%$ absolute level of precision [16], and $1.5 \%$ design effect considered. In addition a none response rate 5\% was utilized and finally a sample size of 604 was determined.

\section{Sampling technique}

The study population was selected using multistage sampling technique. Two stage sampling was used to select the study participants. At the first stage by using simple random sampling two Kebeles was selected from four total Kebeles. At the second stage study participants was selected systematically after allocating the total number of postpartum women (sample) to each of the selected Kebeles proportionally. The study participants were selected by systematic random sampling techniques before interview. Before the actual data collection; community-based survey was done for 7 day to trace the postpartum women (Additional file 1: Figure S1).

\section{Operational definitions}

Knowledge of LAM as a contraception method refers to the study participants' spontaneously mentioned the following three criteria: (a) feeding exclusively with mother's milk; (b) postpartum amenorrhea; (c) infant younger than six months $[3,5,17]$. A binary dependent variable indicating if the study participants mentioned all the above three criteria, it categorized as knowledgeable (1), if not (0).

Antenatal care services use proportion of women who have received antenatal care at least one and above visit either at health center or hospital.

Fertility desire This was defined as the need to have another child in the future as expressed at the time of data collection [18]. The other detail measurements variables are indicated in Additional file 2: Table S1.

\section{Data collection and quality control}

Data was collected via face to face interview at the study participant's home using a structured and pre-tested 
questionnaire. The tool was prepared originally in English and translated to "Tigrigna" and translated back to English in order to maintain internal consistency. Four female diploma midwife holders and a Bachelor of Science in nurse resident supervisor were involved during the data collection period.

\section{Data processing and analysis}

Data were entered using EPI INFO version 7 and exported to STATA version 12 for analysis. Descriptive statistics were presented in the form of tables and texts. To identify factors associated with knowledge of LAM as a method contraceptive, binary logistic regression analysis was conducted. P-value $<0.05$ and $95 \% \mathrm{CI}$ for adjusted odds ratios were used to confirm the statistical significance of the associations [16].

\section{Results}

\section{Socio-demographic characteristics}

In this study, 604 postpartum women were interviewed. From these, 590 (97.7\%) women completely responded to the questioner. The mean age of the study samples was $27.4 \pm 5.0$ years. Two hundred thirty-one (39.2\%) were aged between 25 and 29 years; $3.2 \%$ were teenagers ( $<20$ years). Three hundred eighty-three $(64.9 \%)$ were housewives. Majority (52.2\%) of the study participants had attended secondary and above educational level and $38.5 \%$ of their partner attended primary educational school (Table 1).

\section{Maternal health services use related characteristics}

In this study a total 579 or $98.1 \%$ of the study participants attended at least one antenatal care visits. Five hundred twenty-four of the women had received four or more ANC visits. Five hundred seventy-seven delivered by skill attendants at health institution. Two hundred fifty eight (43.7\%) had received postnatal care follow up either at health center or hospital (Additional file 3: Table S2).

\section{Knowledge of lactational amenorrhea as a contraceptive method during postpartum period}

In this study, the knowledge of lactation amenorrhea as a contraceptive method was found to be fifty-two (8.8\%) [95\% CI (6.4-11\%)].

\section{Knowledge sources on lactational amenorrhea as a contraception method}

Public health institution (38.4\%), health extension worker (30.7\%), relatives, friends and mothers (19.9\%), media (mass media, and print media) (6.7\%) and private health institution (4.3\%) (Fig. 1).
Table 1 Socio-demographic variables in Aksum town, Tigray Region, northern Ethiopia, June 2015

\begin{tabular}{|c|c|c|}
\hline Variables & Frequency (n) & Percentage (\%) \\
\hline \multicolumn{3}{|l|}{ Age } \\
\hline $16-19$ & 19 & 3.2 \\
\hline $20-24$ & 149 & 25.2 \\
\hline $25-29$ & 231 & 39.2 \\
\hline $30-34$ & 126 & 21.4 \\
\hline$\geq 35$ & 65 & 11.0 \\
\hline \multicolumn{3}{|l|}{ Marital status } \\
\hline Married & 543 & 92.0 \\
\hline Others $^{a}$ & 47 & 8.0 \\
\hline \multicolumn{3}{|l|}{ Educational level } \\
\hline No formal education & 80 & 13.6 \\
\hline Primary education & 202 & 34.2 \\
\hline Secondary education and above & 308 & 52.2 \\
\hline \multicolumn{3}{|l|}{ Partner's education $(n=545)$} \\
\hline No formal education & 24 & 4.4 \\
\hline Primary school & 210 & 38.5 \\
\hline Secondary school & 185 & 34.0 \\
\hline Tertiary school & 126 & 23.1 \\
\hline \multicolumn{3}{|l|}{ Occupation } \\
\hline House wife & 383 & 64.9 \\
\hline Government employee & 46 & 7.8 \\
\hline Private employee & 103 & 17.5 \\
\hline Daily labourer & 43 & 7.3 \\
\hline Others $^{b}$ & 15 & 2.5 \\
\hline Partner occupation $(n=545)$ & 125 & 22.9 \\
\hline \multicolumn{3}{|l|}{ Government employee } \\
\hline Private employee & 257 & 47.2 \\
\hline Daily labourer & 131 & 24.0 \\
\hline Others $^{c}$ & 32 & 5.9 \\
\hline
\end{tabular}

a Single, separated, divorced, or widowed, ${ }^{\mathrm{b}}$ Alcohol/Swa seller, farmer, or student, ${ }^{\mathrm{C}}$ Farmer, pension, or guard

Factors associated with knowledge of lactational amenorrhea as a contraceptive method

During the multivariable logistic regression model, maternal educational level, place of birth, postnatal care, visited and counseled for family planning by health extension workers in the last 12 months were found significantly associated with the outcome variable when we adjusted for variables P-value less than 0.2.

Participates who gave birth at health institution were 1.4 times $(\mathrm{AOR}=1.4,95 \% \mathrm{CI} 1.3-4.3)$ more likely have found a sufficient knowledge on lactational amenorrhea method as a method contraceptive than as compare to those who gave birth at home. Women who had postnatal care visit were 1.3 times $(\mathrm{AOR}=1.395 \%$ CI 1.2-3.0) more likely knowledgeable about lactational amenorrhea method as a method of contraception in the extended postpartum period than as compare to those who have no follow up services. Those women who had visited home 


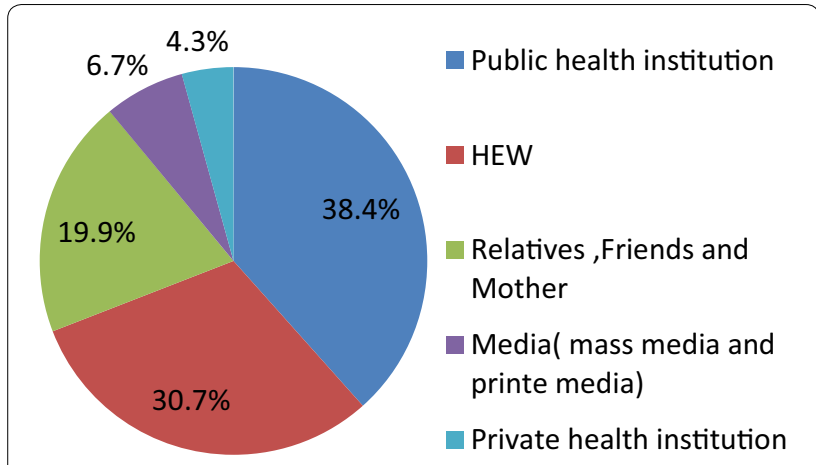

Fig. 1 Knowledge sources on lactational amenorrhea as a contraception method in Aksum town, Tigray Region, northern Ethiopia, June 2015

and counseled for family planning by health extension worker in the last 12 months were 1.5 times $(\mathrm{AOR}=1.5$, 95\% CI 1.3-4.0) more likely to increase knowledge toward lactational amenorrhea method as compare to women who did not visited and counseled about family planning at their home by health extension worker. In addition, study participants with secondary and above maternal education were more likely to be knowledgeable than women with primary and no formal education $(\mathrm{AOR}=1.2,95 \%$ CI 1.1-4.0) (Table 2).

\section{Discussion}

There are a clear evidence show that; lactational amenorrhea method is highly effective contraceptive method for fertility control when the mother is well informed and supported how to use as method of contraception [19]. LAM for postpartum mothers can be used effectively and reliably as a method of contraception [3]. This study is the first to assess the level of knowledge LAM as a method of contraceptive and its determinants in Ethiopia. Therefore, identifying the knowledge gap and potential factors associated with it; is an important step to improve the adoption rate of lactational amenorrhea method as a contraception option and it can help to improve exclusive breast feeding practice [20], in the region particularly in Ethiopia.

This finding show that the knowledge level on lactational amenorrhea method was found 8.8\% (95\% CI 6.4$11 \%)$; this finding higher than a study done in Cairo (1\%) [21]. This might be attributing to the coordinated efforts done by health workers and health extension workers

Table 2 Predictors of lactational amenorrhea method knowledge of postpartum women in Aksum town, Tigray Region, Ethiopia, June 2015

\begin{tabular}{|c|c|c|c|c|c|}
\hline \multirow[t]{2}{*}{ Variable } & \multicolumn{5}{|c|}{ Knowledge of LAM } \\
\hline & Yes & No & COR $(95 \% \mathrm{CI})$ & AOR $(95 \% \mathrm{Cl})$ & P-value \\
\hline \multicolumn{6}{|l|}{ Maternal educational attainment } \\
\hline No formal education & 5 & 75 & Ref & Ref & \\
\hline Primary educational & 24 & 178 & $0.82(0.3-2.24)$ & $0.6(0.1-3.0)$ & \\
\hline Secondary education and above & 23 & 285 & $1.67(1.2-3.0)^{\mathrm{a}}$ & $1.2(1.1-4.0)^{\mathrm{a}}$ & 0.00 \\
\hline \multicolumn{6}{|l|}{ Place of birth } \\
\hline Home & 1 & 12 & Ref & Ref & \\
\hline Health institution & 51 & 526 & $1.16(1.11-9.13)^{\mathrm{a}}$ & $1.4(1.2-4.3)^{\mathrm{a}}$ & 0.04 \\
\hline \multicolumn{6}{|l|}{ PNC } \\
\hline Yes & 21 & 237 & $1.16(1.13-2.0)^{\mathrm{a}}$ & $1.3(1.2-3.0)^{\mathrm{a}}$ & 0.02 \\
\hline No & 31 & 301 & Ref & Ref & \\
\hline \multicolumn{6}{|c|}{ Visited and counseled FP by HEW in the last 12 months } \\
\hline Yes & 42 & 415 & $1.14(1.1-2.5)^{\mathrm{a}}$ & $1.5(1.3-4.0)^{\mathrm{a}}$ & 0.001 \\
\hline No & 10 & 123 & Ref & Ref & \\
\hline \multicolumn{6}{|l|}{ Fertility desire } \\
\hline Yes & 42 & 444 & Ref & Ref & \\
\hline No & 10 & 94 & $1.12(1.1-2.3)^{\mathrm{a}}$ & $1.02(0.30-2.81)$ & 0.13 \\
\hline \multicolumn{6}{|l|}{ Number of live children } \\
\hline 1 & 10 & 172 & Ref & Ref & \\
\hline $2-3$ & 30 & 251 & $0.55(0.23-1.3)$ & $0.4(0.3-1.7)$ & \\
\hline$\geq 4$ & 12 & 115 & $1.14(1.1-2.3)^{\mathrm{a}}$ & $1.7(1.2-7.0)$ & 0.82 \\
\hline
\end{tabular}

FP family planning, HEW health extension worker, PNC postnatal care, Ref reference category

a Statistically associated 
of house to house based health education on maternal health servicers' use.

In this study, study participants with secondary and above educational level were 1.2 times more likely to have knowledge than study participants with no formal and primary education. This statistically significance and positive relationship could be explained by the fact that educated mothers are more knowledgeable on the importance LAM; and also educated mothers are more likely to visit health institution and they may have access to media and written information on lactational amenorrhea method. This association is line with finding reported a study done in eastern Turkey [22].

Place of birth (health facility versus home) and postnatal care services use was found important predictor associated with knowledge of LAM. The possible explanation is study participants who delivered at health facility and attended postnatal care might get an opportunity comprehensive counseling about the modern and traditional contraceptive during their maternal health services utilization. This is line with a study conducted in Niger [23].

In line with previous study done in Niger [23], mothers visited and counseled for family planning by town HEW in the last 12 months prior the study at their home showed an independent associated with the lactational amenorrhea method knowledge (AOR $=1.5$, 95\% CI 1.34.0). This finding suggests that increasing home to home counseling for family planning by town health extension workers a key mechanism to increase the knowledge gap of LAM for postpartum mothers.

\section{Conclusions}

This study demonstrated that the knowledge of LAM as a contraceptive method was found so low. Our findings reinforce that in order to address the knowledge gap of mothers; improving the uptake of maternal health services and strengthening family planning counseling at their home are a key area for improving the knowledge level of LAM.

\section{Limitations}

This study has some limitation limitations: First, it focuses only on the individual level variables. Factors related to community level such as socio-cultural and family planning program related factors did not address in this study. Second, this study has the usual limitation of a cross sectional study. It is difficult to ascertain the association between knowledge of LAM as a method of contraceptive and the predictor variables since they were measured at one point in time.

\section{Additional files}

Additional file 1: Figure S1. Schematic representation of sampling procedure, knowledge of LAM as a contraception method among postpartum women in Aksum town, Tigray Region, northern Ethiopia, June $2015(n=604)$.

Additional file 2: Table S1. Description and measurement of variables, Aksum town, Tigray Region, Ethiopia, June 2015.

Additional file 3: Table S2. Characteristics of maternal health services use in Aksum town, Tigray Region, northern Ethiopia, June 2015.

\section{Abbreviations}

AOR: adjusted odds ratio; $\mathrm{Cl}$ : confidence interval; COR: crude odds ratio; EHSTP: Ethiopian Health Sector Transformation Plan; LAM: Iactation amenorrhea method.

\section{Authors' contributions}

THA wrote the proposal, participated in the data collection, in the statistical analysis and writing the manuscript. AST and AAG participated in data analysis and writing the methodology section. TGW, GKF, BGA and DSB contributed to interpretation of the results, discussion and conclusion. All authors THA, AST, AAG, TGW, GKF, BGA and DSB revised scientifically reviewed the manuscript. All authors read and approved the final manuscript.

\section{Author details}

${ }^{1}$ School of Public Health, College of Health Sciences, Aksum University, P.O.Box: 1010, Aksum, Tigray, Ethiopia. ${ }^{2}$ Institute of Public, College of Medicine and Health Sciences, University of Gondar, Gondar, Ethiopia. ${ }^{3}$ School of Nursing, College of Health Sciences, Mekelle University, Mekelle, Tigray, Ethiopia.

\section{Acknowledgements}

The authors would like to acknowledge for all study participants and data collectors.

\section{Competing interests}

The authors declare that they have no competing interests.

Availability of data and materials

All the required data are presented with in the manuscript.

\section{Consent for publication}

This article does not contain any individual person's data in the form of image or video. Hence consent for publication is not applicable.

\section{Ethics approval and consent to participate}

This study protocol was granted by the Institutional Review Board of the Institute of Public Health (IRB), University of Gondar. Informed written consent was obtained from each study participants to confirm willingness for participation after explaining the objective of the study. The interview was done in a private location. To ensure the study participants confidentiality; name, personal identifiers was not included in the questionnaire.

Funding

There was no any funding.

\section{Publisher's Note}

Springer Nature remains neutral with regard to jurisdictional claims in published maps and institutional affiliations.

Received: 16 August 2018 Accepted: 31 August 2018

Published online: 03 September 2018 


\section{References}

1. Peterson A, Peŕez-Escamilla R, Labboka M, Hight V, Von Hertzen H, Van Look P. Multicenter study of the lactational amenorrhea method (LAM) III: effectiveness, duration, and satisfaction with reduced client-provider contact. Contraception. 2000;62(5):221-30.

2. World Health Organization [WHO]. Medical eligibility criteria for contraceptive use. Geneva: World Health, Organization; 2015.

3. Kennedy $\mathrm{KI}$, Visness CM. Contraceptive efficacy of lactational amenorrhoea. Lancet. 1992;339(8787):227-30.

4. Ramos R, Kennedy KI, Visness CM. Effectiveness of lactational amenorrhoea in prevention of pregnancy in Manila, the Philippines: non-comparative prospective trial. BMJ. 1996;313(7062):909.

5. Labbok M, Perez A, Valdes V, Sevilla F, Wade K, Laukaran V, et al. The Lactational Amenorrhea Method (LAM): a postpartum introductory family planning method with policy and program implications. Adv Contracept. 1994;10(2):93-109.

6. Kennedy KI, Rivera R, McNeilly AS. Consensus statement on the use of breastfeeding as a family planning method. Contraception. 1989;39(5):477-96.

7. Ross JA, Winfrey WL. Contraceptive use, intention to use and unmet need during the extended postpartum period. Int Fam Plan Perspect. 2001;27:20-7.

8. Winfrey W, Kshitiz R. Use of family planning in the postpartum period, DHS comparative report no. 36. Rockville: ICF International; 2014.

9. Central Statistical Agency (CSA) [Ethiopia] and ICF. Ethiopia demographic and health survey 2016. Addis Ababa: CSA and ICF; 2016.

10. Federal Democratic Republic of Ethiopia [FDRE], Ministry of Health [MoH]. Health Sector Transformation Plan [HSTP]. 2015/16-2019/20, Addis Ababa, Ethiopia; 2015.

11. USAID and MCHIP-FP. Family planning needs during the first two year postpartum period in Ethiopia. 2012

12. Borda M, Winfrey W. Postpartum fertility and contraception: an analysis of findings from 17 countries. Baltimore: Jhpiego; 2010.
13. Bongiovanni A, Samamh MMA, AISarabi RH, Masri SD, Zehner ER, Huffman SL. The lactational amenorrhea method (LAM) in Jordan increases modern contraception use in the extended postpartum period. Jordan: AED (Linkages); 2005.

14. Hardy E, Santos LC, Osis MJ, Carvalho G, Cecatti JG, Faundes A. Contraceptive use and pregnancy before and after introducing lactational amenorrhea (LAM) in a postpartum program. Adv Contracept. 1998;14(1):59-68.

15. Aksum town health office. Aksum town health office report. Ethiopia: Tigray Region; 2015.

16. Lemeshow S, Hosmer D Jr, Klar J, Lwanga S. Adequacy of Sample Size in Health Sciences. New York: John Wiley and Sons; 1990

17. Vekemans M. Postpartum contraception: the lactational amenorrhea method. Eur J Contracep Reprod Health Care. 1997;2(2):105-11.

18. Matovu JK, Makumbi F, Wanyenze RK, Serwadda D. Determinants of fertility desire among married or cohabiting individuals in Rakai, Uganda: a cross-sectional study. Reprod Health. 2017;14(1):2.

19. Van Look PF. Lactational amenorrhoea method for family planning. $\mathrm{Br}$ Med J. 1996;313(7062):893.

20. Panzetta S, Shawe J. Lactational amenorrhoea method: the evidence is there, why aren't we using it? J Fam Plann Reprod Health Care. 2013;39(2):136-8

21. Khella AK, Fahim HI, Issa AH, Sokal DC, Gadalla MA. Lactational amenorrhea as a method of family planning in Egypt. Contraception. 2004;69(4):317-22.

22. Pirincci $E$, Taşdemir R, Oguzoncul AF. Knowledge of lactational amenorrhea as a contraceptive method among mothers of infants aged 0-6 months in a district, Eastern Turkey. Int J Community Med Public Health. 2017;3(6):1363-70

23. Sipsma HL, Bradley EH, Chen PG. Lactational amenorrhea method as a contraceptive strategy in Niger. Matern Child Health J. 2013;17(4):654-60.
Ready to submit your research? Choose BMC and benefit from:

- fast, convenient online submission

- thorough peer review by experienced researchers in your field

- rapid publication on acceptance

- support for research data, including large and complex data types

- gold Open Access which fosters wider collaboration and increased citations

- maximum visibility for your research: over $100 \mathrm{M}$ website views per year

At $\mathrm{BMC}$, research is always in progress.

Learn more biomedcentral.com/submissions 